\title{
Development and Validation of an HPLC Method for the Analysis of Chlorpropham and 3-Chloroaniline in Potato Extracts
}

\author{
Nidhal M. Sher Mohammed, ${ }^{1}$ T. H. Flowers, ${ }^{2}$ and H. J. Duncan ${ }^{2}$ \\ ${ }^{1}$ School of Chemistry, Faculty of Science, University of Zakho, Zakho, Kurdistan Region, Iraq \\ ${ }^{2}$ School of Chemistry, Faculty of Science and Engineering, University of Glasgow, Joseph Black Building, Glasgow G12 8QQ, UK
}

Correspondence should be addressed to Nidhal M. Sher Mohammed; nidhalsher@yahoo.com

Received 28 September 2014; Accepted 15 December 2014; Published 29 December 2014

Academic Editor: Toyohide Takeuchi

Copyright (C) 2014 Nidhal M. Sher Mohammed et al. This is an open access article distributed under the Creative Commons Attribution License, which permits unrestricted use, distribution, and reproduction in any medium, provided the original work is properly cited.

\begin{abstract}
Chlorpropham (CIPC) is the main sprout inhibitor used by potato industry. There is concern about the residues of CIPC and its degradation product 3-chloroaniline, 3-CA; hence, analytical methods are required to analyse their residues in potato samples. An HPLC-UV method was developed and validated for the separation and quantification of these compounds using propham (IPC) as an internal standard. The chromatographic conditions required to achieve good separation were $60 \%$ mobile phase of methanol, $15-$ minute run time at a flow rate of $1.5 \mathrm{~mL} / \mathrm{min}$, and a detection wavelength of $210 \mathrm{~nm}$ using Phenomenex (ODS-2 $250 \mathrm{~mm} \times 4.60 \mathrm{~mm}$ $5 \mu \mathrm{m}$ Sphereclone) column at an ambient temperature. The method was validated for precision, linearity, the limit of detection (LOD) and the limit of quantification (LOQ), producing high precision through RSD $\leq 0.03 \%$, and acceptable criteria of the coefficient of determination $\left(R^{2}\right)$ of the calibration curves (0.990). LOD values of CIPC and 3-CA were approximately $0.01 \mu \mathrm{g} / \mathrm{mL}$ whereas the LOQ values were approximately $0.04 \mu \mathrm{g} / \mathrm{mL}$ using repeated injection approach. The proposed HPLC method was compared with the standard GC method of the CIPC residues extracted showing good agreement $\left(R^{2}=0.99\right)$. Despite using the same extract, the recovery results for the proposed HPLC method were $13 \%$ higher than GC analysis.
\end{abstract}

\section{Introduction}

Chlorpropham (isopropyl 3-chlorophenyl carbamate) or CIPC is the main sprout inhibitor currently used by potato industry. Propham (IPC) is a herbicide from the same group as chlorpropham; it was applied commercially to prevent sprouting or in combination with chlorpropham, but currently its application is being banned in most countries. CIPC is a compound of the well-known group of $\mathrm{N}$ phenyl carbamates which may undergo rapid degradation under unsuitable solvent and excessive heating conditions releasing 3-CA [1-5]. For public health and environmental consideration, there is concern about their residues $[6,7]$; hence, analytical methods are required to analyse the residues of these phenylcarbamates in potato and environmental samples particularly CIPC and its degradation product 3chloroaniline 3-CA.
HPLC is used to determine carbamate pesticides residues mainly to overcome the thermal liability problems of these pesticides when using gas chromatography (GC). However, a lack of a specific, sensitive detector hinders a suitable level of separation for a number of pesticides. Adequate sensitivity and excellent specificity can be provided by ultraviolet (UV) or electrochemical HPLC detection [8]. Using HPLC-UV seems to be more appropriate as a final step to analyse phenylcarbamate pesticides [9-13].

In reviewing the literature, two simple RP-HPLC methods with external and internal standards were developed for the determination of CIPC in emulsifiable concentrates [14]. Samples were diluted with methanol containing internal standard of 4-nitrodiphenyl ether. The chromatographic conditions were set using $60 \%$ methanol, at a flow rate of $2 \mathrm{~mL} / \mathrm{min}$ giving retention times of 4.4 minutes for CIPC and 5.9 minutes for the internal standard. The sample injection 
volume was $10 \mu \mathrm{L}$ and the detection was set at a wavelength of $240 \mathrm{~nm}$. Calibration and quantification were carried out using pure standards of CIPC to achieve good linearity at a concentration range of between 0.01 and $1.5 \mathrm{~g} / \mathrm{L}$ with a detection limit for CIPC of $0.00039 \mathrm{~g} / \mathrm{L}$. The internal standard method reported slight improvement of the confidence limit and the relative standard deviation relative to the external standard method.

HPLC-UV methods have been used to analyse both CIPC and propham (IPC) in potato products [12, 15-18]. These methods have not included the analysis of CIPC in combination with its degradation products in particular 3CA.

The main objective of this work was to develop and validate an analytical HPLC-UV method for the simultaneous analysis of CIPC and its metabolite 3-CA using IPC as internal standard.

\section{Materials and Methods}

2.1. Reagents. Chlorpropham (95\%), 3-chloroaniline (99\%), and propham (IPC) (99\%) were purchased from SigmaAldrich Chemi GmbH (Germany); methanol (HPLC grade) was supplied by Fisher Scientific International Company (UK). Stock solutions of $10000 \mu \mathrm{g} \mathrm{m}^{-1}$ of each compound (CIPC, IPC, and 3-CA) were prepared in methanol. These individual stock standard solutions were stored in a refrigerator at $4^{\circ} \mathrm{C}$ and were used to prepare the working solutions at different concentrations. The standard solutions were warmed to room temperature of $20^{\circ} \mathrm{C}$ prior to injection.

2.2. HPLC System. The HPLC system used comprised a GILSON 234 autosampler, Cecil 1100 Series pump, Phenomenex Security Guard (part number KJO-4282) guard column with analytical column Phenomenex (ODS-2 $250 \mathrm{~mm}$ $\times 4.6 \mathrm{~mm} 5 \mu \mathrm{m}$ Sphereclone), and a Thermo Separation SpectraSERIES UV100 detector coupled with Dionex Peaknet software.

2.3. Preparation of the Mobile Phase. The mobile phase for HPLC analysis was prepared from methanol and water $(\mathrm{v} / \mathrm{v})$. The water used for preparation of the mobile phase was supplied from an Elga Purelab Option deioniser model LA613 and then filtered through a Supor-200 membrane filter $(47 \mathrm{~mm} 0.2 \mu \mathrm{m})$. The mobile phase was degassed using helium gas. Stabilising the temperature was controlled by insulating the mobile phase by placing the reservoir of the mobile phase in a polystyrene box. In addition, the mobile phase was prepared the day before it was required for analysis and kept overnight at a fixed room temperature of $20^{\circ} \mathrm{C}$.

\subsection{Optimising the Separation of CIPC, IPC, and 3-CA Using} Different Strengths of the Mobile Phase. The effect of the different concentrations of the mobile phase was investigated to optimise the separation of intended compounds and construct a basic background for developing an HPLC separation method with high resolution and rapid analysis of the eluted compounds. In order to achieve this, several concentrations of methanol $(70 \%, 65 \%, 60 \%, 55 \%$, and $50 \%)$ in the mobile phase were tested to achieve a good resolution of the mixture of components peaks with the minimum run time. All analyses were performed at a detection wavelength of $210 \mathrm{~nm}$, pump flow rate of $1.5 \mathrm{~mL} / \mathrm{min}$, an injection volume of $20 \mu \mathrm{L}$, and the column at ambient temperature.

\subsection{Determination of the Precision of the Standard Solutions.} Five replicate injections of $1 \mu \mathrm{g} / \mathrm{mL}$ of a mixture of CIPC, IPC, and 3-CA were injected to measure the precision of the standard solution by calculating the relative standard deviation (RSD\%) as described in recent study [19].

2.6. Linearity of the Calibration Curve. The linearity of the calibration curve was tested at three ranges of concentrations $(0.02-0.1,0.2-1.0$, and $2-10 \mu \mathrm{g} / \mathrm{mL})$ prepared as three series of standard solutions of a mixture of CIPC, IPC, and 3-CA in methanol. The different sets of standards were injected as duplicates into HPLC system. Linearity was evaluated according to the relationship between the peak area of the compound and its concentration. Excel software was employed to plot the calibration curve for each compound in the solution. From the regression line, the coefficient of determination $\left(R^{2}\right)$ was obtained to statistically assess the linear relationship.

2.7. Determination of $L O D$ and $L O Q$. The LOD and LOQ were estimated for three compounds as mentioned in recent study [19], applying two approaches including statistical regression of the low concentration range of $0.02-0.1 \mu \mathrm{g} / \mathrm{mL}$ and ten replicate injections of mixed solution at the low concentration of $0.05 \mu \mathrm{g} / \mathrm{mL}$ of CIPC, IPC, and 3-CA.

2.8. Correlation between the Proposed HPLC Method and GC Analysis. To prove the applicability and reliability of the proposed HPLC method, it was compared to the standard GC method for residue analysis of CIPC as described in recent study [20]. The Soxhlet extraction procedure was applied to extract CIPC from treated potatoes. Randomly, 29 individual potato tubers which had been treated with CIPC were chosen from large commercial stores. After washing and drying procedures were performed, the peel from each tuber was placed into a cellulose thimble, which contained $10 \mathrm{~g}$ of the drying agent sodium sulphate to remove the water from the potato peel. The thimble was plugged with cotton wool and placed into a Soxhlet extraction unit prior to extraction with $150 \mathrm{~mL}$ of hexane solvent. The peel was extracted for approximately two hours after the first reflux. The extract in the round bottom flask was quantitatively transferred to a $100 \mathrm{~mL}$ volumetric flask and made up to volume. The extract was divided into two portions (each $50 \mathrm{~mL}$ ) for simultaneous analysis by HPLC and GC. For HPLC analysis, the extract was filtered through a $0.2 \mu \mathrm{m}$ PTFE (Teflon) membrane syringe filter prior to analysis. For GC analysis, the other $50 \mathrm{~mL}$ extract was concentrated using a rotary evaporator (Büchi Rotavapor RE111) coupled to a water bath (Grant JB2 thermostat) at $35^{\circ} \mathrm{C}$ to evaporate the solvent. The concentrated extract was transferred quantitatively to a 
volumetric flask; then $200 \mu \mathrm{L}$ of the $1000 \mu \mathrm{g} / \mathrm{mL}$ propham (IPC) as internal standard was added and the volume was made up to $2 \mathrm{~mL}$ for analysis by GC.

GC analysis was performed on a Hewlett Packard HP 5890 A gas chromatography with a Flame Ionisation Detector (FID), HP 7633A autosampler unit, and DB-1 column (30 m, $0.53 \mathrm{~mm}$ i.d., and $1.5 \mu \mathrm{m}$ film thickness). The oven program was started at $40^{\circ} \mathrm{C}$ for 4 minutes, then increased at $55^{\circ} \mathrm{C} / \mathrm{min}$ up to $175^{\circ} \mathrm{C}$, and held for 10 minutes and then $15^{\circ} \mathrm{C} / \mathrm{min}$ up to $230^{\circ} \mathrm{C}$ and held for 10 minutes. The injector temperature was set at $220^{\circ} \mathrm{C}$ and the detector at $250^{\circ} \mathrm{C}$ setting the injection volume to $2 \mu \mathrm{L}$.

\section{Results and Discussion}

3.1. Optimising the Separation of CIPC, IPC, and 3-CA Using Different Strengths of the Mobile Phase. The chromatographic conditions were set based on an isocratic method using methanol/water as the mobile phase. Propham (IPC) was chosen as the internal standard due to its similarity in structure to chlorpropham with the only difference being the absence of one chlorine atom in the phenyl ring (Figure 1).

The initial chromatographic conditions provided an overview of the identification and optimisation of the separation of studied compounds from their mixture. Testing different concentration strengths of the mobile phase showed good separation of CIPC, IPC, and 3-CA at $60 \%$ methanol with retention times of $13,6.5$, and 5 minutes, respectively (Figure 2). However, the impurity peak has little effect on the background of the baseline of the 3-CA peak. The source of the impurity peak might be caused by the methanol solvent; it was present in small amounts in all available batches of methanol, which were purchased from the same supplier. This impurity peak can be considered particularly at very low concentration of 3-CA. Overall, $60 \%$ was considered to provide acceptable resolution of all peaks with a $15 \mathrm{~min}$ chromatographic run time.

This test exhibited good UV absorbance for all compounds at a wavelength of $210 \mathrm{~nm}$, although the peak height of propham was quite small due to its absorbance being very low at a wavelength of $210 \mathrm{~nm}$ compared with its $\lambda_{\max } 200 \mathrm{~nm}$. The separation between the compounds was dependent on their polarity. Because of the wide range of polarities between these compounds, the higher polarity compound was eluted first from the HPLC column. For that reason, the peaks of 3CA and IPC appeared first and second, respectively, before the final peak of CIPC.

The peaks of eluted compounds were identified in the chromatogram through a comparison of the retention times based on an analysis of a standard mixture and individual reference standards. The same chromatographic conditions were applied during running these standards. In addition, the standards of eluted compounds excluding one compound were analysed to confirm the identity of the peaks and exact retention time of each component.

No effect of the temperature on the separation was noticed. Setting the HPLC column at ambient temperature ( $20^{\circ} \mathrm{C}$ ) proved to be sufficient to obtain optimum separation.

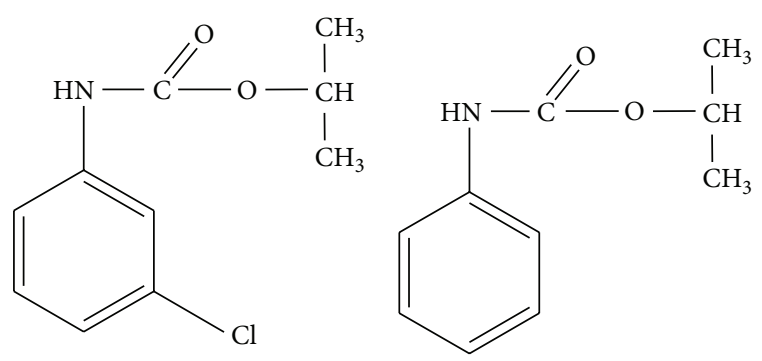

(a)

(b)

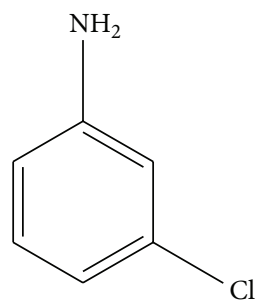

(c)

FigURE 1: The chemical structure of (a) chlorpropham, (b) propham, and (c) 3-chloroaniline.

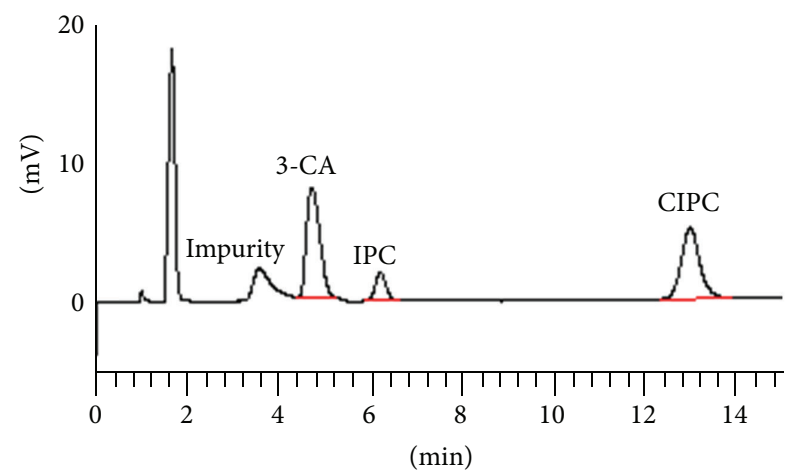

FigURE 2: HPLC chromatogram of $1 \mu \mathrm{g} / \mathrm{mL}$ mixture of CIPC, IPC, and 3-CA at ambient temperature.

TABLE 1: Coefficients of determination of the calibration curve for studied compounds at the different ranges in concentration.

\begin{tabular}{lcc}
\hline Compound & $\begin{array}{c}\text { Concentration } \\
\text { range } \\
(\mu \mathrm{g} / \mathrm{mL})\end{array}$ & $\begin{array}{c}\text { Coefficient of } \\
\text { determination }\left(R^{2}\right)\end{array}$ \\
\hline \multirow{3}{*}{ CIPC } & $0.02-0.1$ & 0.997 \\
& $0.2-1.0$ & 0.991 \\
& $2.0-10$ & 1.000 \\
\hline \multirow{2}{*}{ IPC } & $0.02-0.1$ & 0.983 \\
& $0.2-1.0$ & 0.995 \\
$3-\mathrm{CA}$ & $2.0-10$ & 1.000 \\
& $0.02-0.1$ & 0.999 \\
& $0.2-1.0$ & 0.999 \\
& $2.0-10$ & 1.000 \\
\hline
\end{tabular}


TABLE 2: LOD and LOQ values based on the repeatability injections $(n=10)$ of $0.05 \mu \mathrm{g} / \mathrm{mL}$ of a mixed standard solution of CIPC, IPC, and $3-\mathrm{CA}$ and the statistical data for the calibration curve in the range $0.02-0.1 \mu \mathrm{g} / \mathrm{mL}$.

\begin{tabular}{|c|c|c|c|c|c|c|}
\hline \multirow{2}{*}{ Assessed approach } & \multicolumn{3}{|c|}{$\mathrm{LOD}(\mu \mathrm{g} / \mathrm{mL})$} & \multicolumn{3}{|c|}{ LOQ $(\mu \mathrm{g} / \mathrm{mL})$} \\
\hline & CIPC & IPC & 3-CA & CIPC & IPC & 3-CA \\
\hline Calibration curve $(0.02-0.1 \mu \mathrm{g} / \mathrm{mL})$ & 0.006 & 0.014 & 0.003 & 0.019 & 0.048 & 0.010 \\
\hline Injection repeatability $(0.05 \mu \mathrm{g} / \mathrm{mL})$ & 0.011 & 0.001 & 0.013 & 0.036 & 0.002 & 0.042 \\
\hline
\end{tabular}

3.2. Determination of Precision of Standard Solutions. The precision in terms of repeatability of five replicate injections was determined for CIPC, IPC, and 3-CA through the RSD\% to be $0.03,0.02$, and 0.01 , respectively. RSD $\%$ results indicated acceptable criteria for precision and repeatability were less than $1 \%$.

3.3. Assessment of the Linearity of the Calibration Curve. Linearity was demonstrated by constructing a calibration curve using five concentration levels of standard solutions for each of the three ranges of concentration. Three calibration curves were plotted for each compound in this test. The coefficient of determination $\left(R^{2}\right)$ was employed to evaluate the linearity of the regression line. The results presented in Table 1 show $R^{2}$ values were $>0.990$ with the exception of IPC at the lowest concentration range $(0.02-0.1 \mu \mathrm{g} / \mathrm{mL})$ where the $R^{2}$ was 0.983 . This slightly lower value for the coefficient of determination of IPC can be attributed to a low response of this compound at the detection wavelength used $(210 \mathrm{~nm})$. From the $R^{2}$ values obtained, it can be concluded that the linearity was acceptable for compounds at the three ranges of concentration tested.

3.4. Determination of the LOD and the LOQ. The LOD and LOQ were calculated for the three compounds using two approaches. The results are summarised in Table 2 and show no large difference between the calibration curve and the repeated injection approach. The very low LOD and LOQ values for IPC using the repeated injection approach are probably unrealistic in view of the small peak area due to the weak response at $210 \mathrm{~nm}$. Considering these results, the method is sufficient to determine CIPC and 3-CA residues in potato and environmental samples.

3.5. Correlation between the Proposed HPLC Method and GC Analysis. For final validation of the proposed HPLC method, it was compared with the GC method of the CIPC residues extracted by Soxhlet extraction through linear regression as shown in Figure 3.

It is apparent from the figure that the correlation between the two analyses shows good agreement through the coefficient of determination of $R^{2}(0.99)$. Despite using the same extract of Soxhlet extraction and the same stock standard solution for both analyses, the recovery between the two analyses of the extract is different, showing 13\% higher results for the proposed HPLC method than GC analysis.

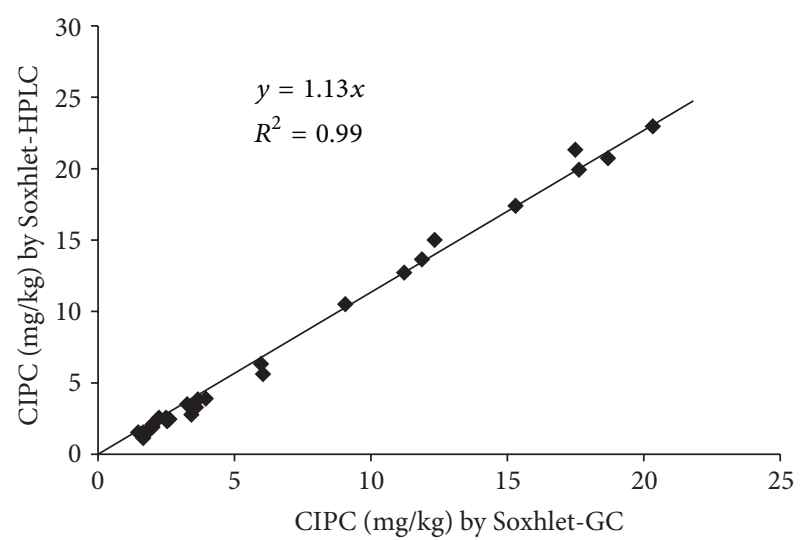

FIGURE 3: The correlation between CIPC residues in treated potato tuber as determined by both HPLC and GC analysis.

\section{Conclusion}

No HPLC-UV method for the simultaneous analysis of chlorpropham and its major metabolite 3-chloroaniline in potatoes and environmental samples was documented in the literature. A successful and rapid analytical method was developed and validated for the separation and quantification of these compounds using propham as an internal standard. Furthermore, this project was undertaken during a global shortage of acetonitrile in 2008. It was therefore essential to develop and validate a method using an alternative solvent and methanol was selected for this purpose.

The new HPLC method was validated through comparison with standard GC method. The proposed method showed results for CIPC residues that were approximately 13\% higher than GC method.

\section{Conflict of Interests}

The authors declare that there is no conflict of interests regarding the publication of this paper.

\section{References}

[1] C. Przybylski and V. Bonnet, "Combination of ${ }^{1} \mathrm{H}$ nuclear magnetic resonance spectroscopy and mass spectrometry as tools for investigation of the thermolytic and solvolytic effects. Case of carbamates analysis," Journal of Chromatography A, vol. 1216, no. 23, pp. 4787-4797, 2009.

[2] M. J. Smith, S. Müller, W. Sander, and G. Bucher, "Mechanisms of the thermal decay of chlorpropham," Journal of Hazardous Materials, vol. 246-247, pp. 154-162, 2013. 
[3] P. C. Kearney and D. D. Kaufman, "Enzyme from soil bacterium hydrolyzes phenylcarbamate herbicides," Science, vol. 147, no. 3659, pp. 740-741, 1965.

[4] J. Hajšlová and J. Davídek, "Indirect gas chromatographic determination of IPC and CIPC in potato tubers," Food/Nahrung, vol. 29, no. 5, pp. 487-490, 1985.

[5] W. H. Gutenmann and D. J. Lisk, "Herbicide residues, electron affinity residue determination of CIPC, monuron, diuron, and linuron by direct hydrolysis and bromination," Journal of Agricultural and Food Chemistry, vol. 12, no. 1, pp. 46-48, 1964.

[6] M. Sihtmäe, M. Mortimer, A. Kahru, and I. Blinova, "Toxicity of five anilines to crustaceans, protozoa and bacteria," Journal of the Serbian Chemical Society, vol. 75, no. 9, pp. 1291-1302, 2010.

[7] B. L. Worobey and W.-F. Sun, "Isolation and identification of chlorpropham and two of its metabolites in potatoes by GCMS," Chemosphere, vol. 16, no. 7, pp. 1457-1462, 1987.

[8] R. D. Voyksner, J. T. Bursey, and E. D. Pellizzari, "Analysis of selected pesticides by high-performance liquid chromatography-mass spectrometry," Journal of Chromatography A, vol. 312, no. 1, pp. 221-235, 1984.

[9] M. J. Santos Delgado, S. Rubio Barroso, G. Toledano FernándezTostado, and L. M. Polo-Díez, "Stability studies of carbamate pesticides and analysis by gas chromatography with flame ionization and nitrogen-phosphorus detection," Journal of Chromatography A, vol. 921, no. 2, pp. 287-296, 2001.

[10] J. M. Soriano, B. Jiménez, G. Font, and J. C. Moltó, “Analysis of carbamate pesticides and their metabolites in water by solid phase extraction and liquid chromatography: a review," Critical Reviews in Analytical Chemistry, vol. 31, no. 1, pp. 19-52, 2001.

[11] L. Sun and H. K. Lee, "Optimization of microwave-assisted extraction and supercritical fluid extraction of carbamate pesticides in soil by experimental design methodology," Journal of Chromatography A, vol. 1014, no. 1-2, pp. 165-177, 2003.

[12] E. Orejuela and M. Silva, "Determination of propham and chlorpropham in postharvest-treated potatoes by liquid chromatography with peroxyoxalate chemiluminescence detection," Analytical Letters, vol. 37, no. 12, pp. 2531-2543, 2004.

[13] M. LeDoux, "Analytical methods applied to the determination of pesticide residues in foods of animal origin. A review of the past two decades," Journal of Chromatography A, vol. 1218, no. 8 , pp. 1021-1036, 2011.

[14] A. P. Heras and F. Sánchez-Rasero, "Determination of carbamic herbicides by high performance liquid chromatography (HPLC). II. Chlorpropham," Journal of Liquid Chromatography, vol. 5, no. 2, pp. 327-335, 1982.

[15] A. M. Wilson, A. A. Bushway, and R. J. Bushway, "Residue analysis of isopropyl $\mathrm{N}$-(3-chlorophenyl)carbamate in fruits and vegetables using high-performance liquid chromatography," Journal of Agricultural and Food Chemistry, vol. 29, no. 4, pp. 746-749, 1981.

[16] M. Königer and P. R. Wallnöfer, "Fate of sprout inhibitors propham (IPC) and chlorpropham (CIPC) in potatoes in relation to different cooking techniques," Deutsche LebensmittelRundschau, vol. 94, no. 7, pp. 229-231, 1998.

[17] A. S. Arribas, E. Bermejo, M. Chicharro, and A. Zapardiel, "Application of matrix solid-phase dispersion to the propham and maleic hydrazide determination in potatoes by differential pulse voltammetry and HPLC," Talanta, vol. 71, no. 1, pp. 430436, 2007.

[18] H. Lee, M. Riu, E. Kim et al., "A single residue method for the determination of chlorpropham in representative crops using high performance liquid chromatography," Journal of the Korean Society for Applied Biological Chemistry, vol. 56, no. 2, pp. 181-186, 2013.

[19] N. S. Mohammed, T. H. Flowers, and H. J. Duncan, "HPLC-UV method development and validation of potato sprout inhibitor 1,4-dimethylnaphthalene using different systems," Chromatography Research International, vol. 2014, Article ID 467485, 6 pages, 2014.

[20] W. A. Khan, H. J. Duncan, A. K. Baloch, and G. McGowan, "Methodology development for routine estimation of chlorpropham in commercial potato stores," Czech Journal of Food Sciences, vol. 30, no. 1, pp. 67-73, 2012. 

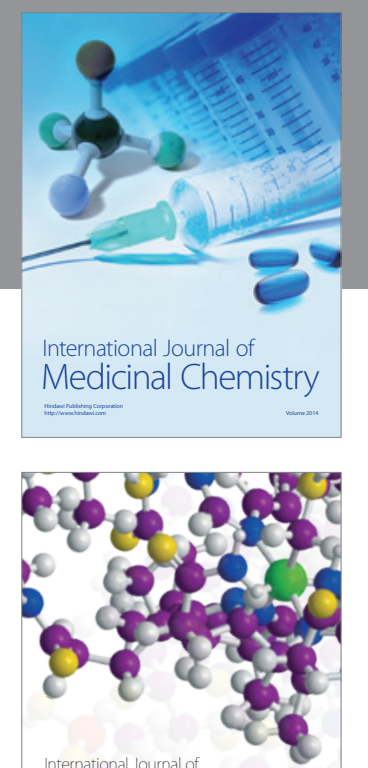

\section{Carbohydrate} Chemistry

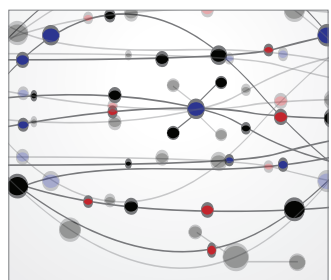

The Scientific World Journal
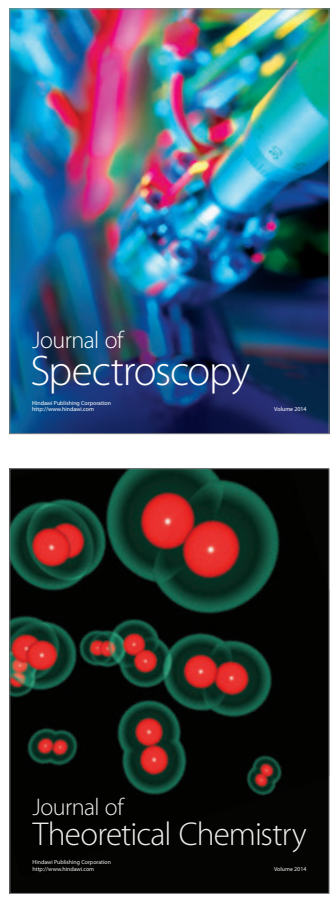
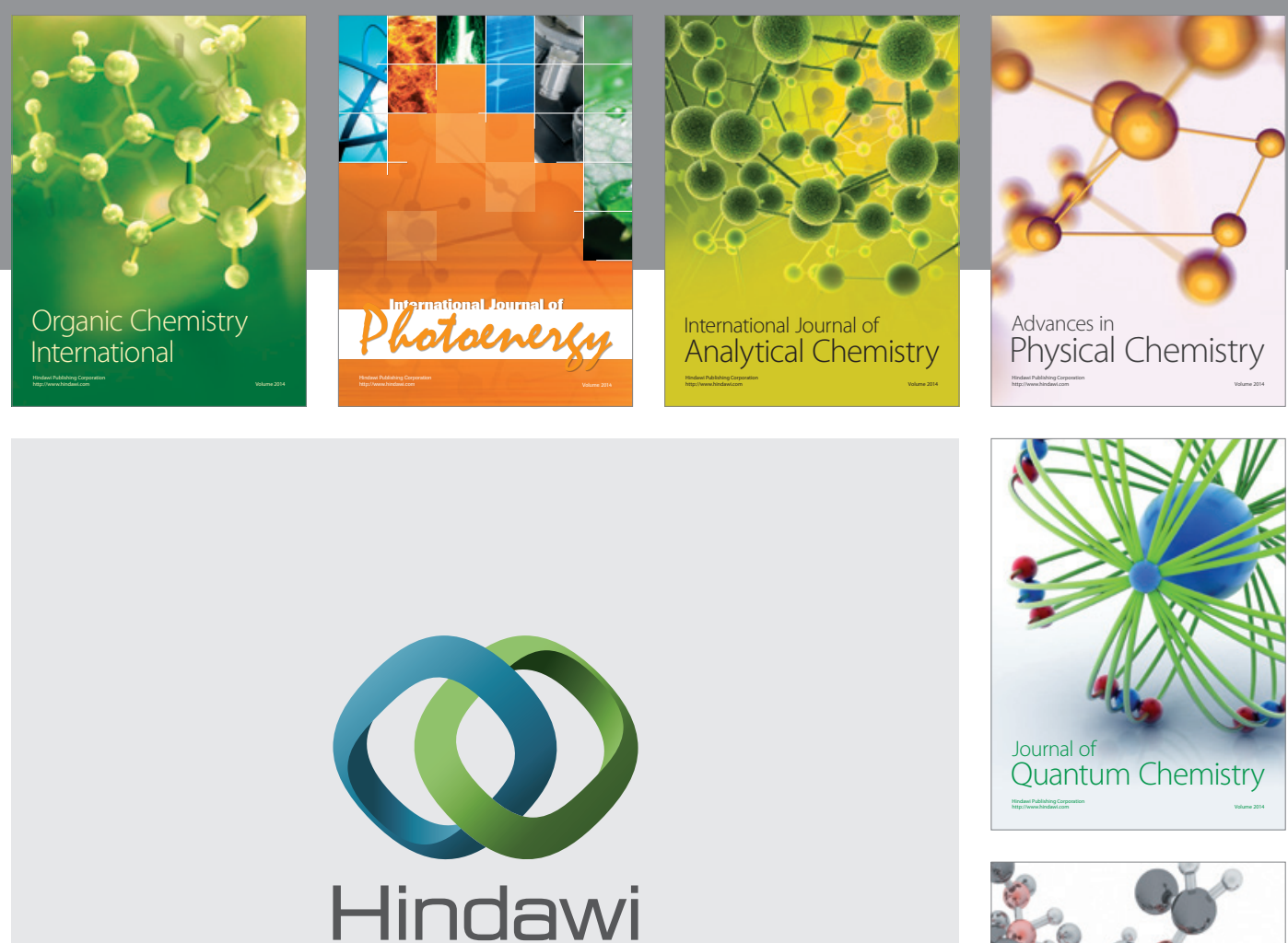

Submit your manuscripts at

http://www.hindawi.com

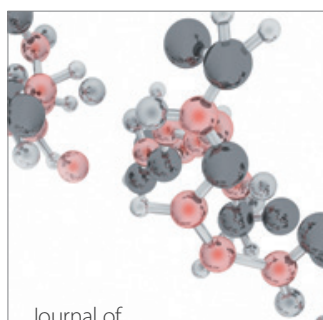

Analytical Methods

in Chemistry

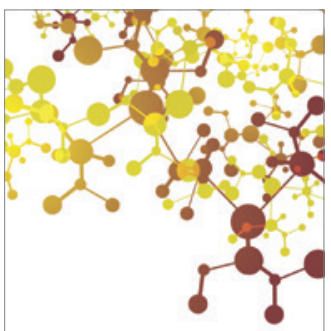

Journal of

Applied Chemistry

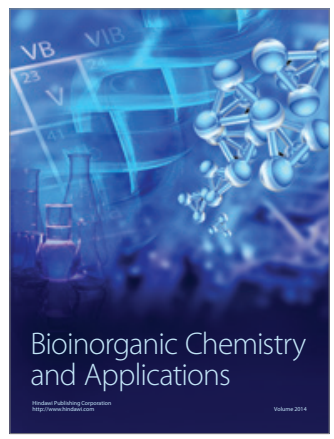

Inorganic Chemistry
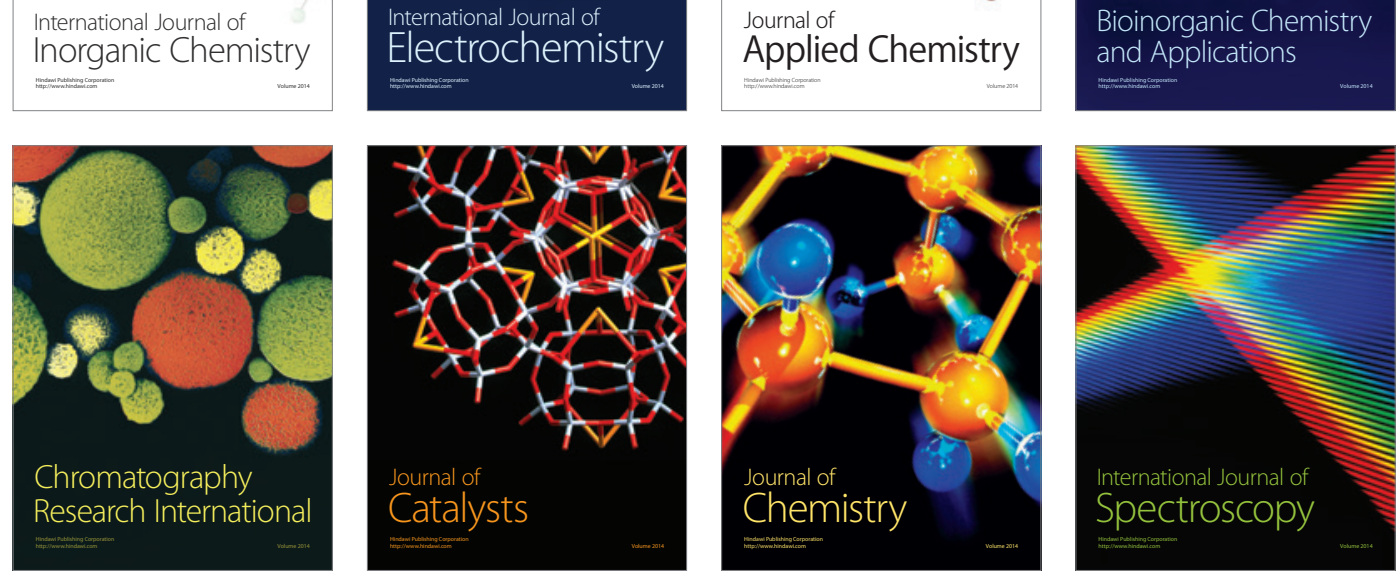